\title{
1 The North Atlantic Oscillation synchronises fruit production in western \\ 2 European forests
}

3 Authors: Marcos Fernández-Martínez *ab, Sara Vicca c, Ivan A. Janssens c ${ }^{\text {, }}$ Josep Maria

4 Espelta $^{b}$ and Josep Peñuelas ab.

5

6 Addresses:

7 a CSIC, Global Ecology Unit, CREAF-CSIC-UAB, Cerdanyola del Vallès 08193, Catalonia,

8 Spain

9 b CREAF, Cerdanyola del Vallès 08193, Catalonia, Spain.

$10{ }^{\mathrm{C}}$ Centre of Excellence PLECO (Plant and Vegetation Ecology), Department of Biology,

11 University of Antwerp, 2610 Wilrijk, Belgium.

12

13 "Corresponding author:

14 Marcos Fernández-Martínez

15 Tel: +34 935814851

16 E-mail address: m.fernandez@creaf.uab.cat

17

This is the peer reviewed version of the following article: Fernández-Martínez, M., Vicca, S., Janssens, I. A., Espelta, J. M. and Peñuelas, J. (2016), The North Atlantic Oscillation synchronises fruit production in western European forests. Ecography., which has been published in final form at doi:10.1111/ecog.02296. This article may be used for non-commercial purposes in accordance with Wiley Terms and Conditions for Self-Archiving." 


\section{Abstract}

Weather and its lagged effects have been associated with interannual variability and synchrony of fruit production for several tree species. Such relationships are used often in hypotheses relating interannual variability in fruit production with tree resources or favourable pollinating conditions and with synchrony in fruit production among sites through the Moran effect (the synchronisation of biological processes among populations driven by meteorological variability) or the local availability of pollen. Climatic teleconnections, such as the North Atlantic Oscillation (NAO), representing weather packages, however, have rarely been correlated with fruit production, despite often being better predictors of ecological processes than is local weather. The aim of this study was to test the utility of seasonal NAO indices for predicting interannual variability and synchrony in fruit production using data from 76 forests of Abies alba, Fagus sylvatica, Picea abies, Pseudotsuga menziesii, Quercus petraea, and Q. robur distributed across central Europe. Interannual variability in fruit production for all species was significantly correlated with seasonal NAO indices, which were more prominently important predictors than local meteorological variables. The relationships identified by these analyses indicated that proximal causes were mostly responsible for the interannual variability in fruit production, supporting the premise that local tree resources and favourable pollinating conditions are needed to produce large fruit crops. Synchrony in fruit production between forests was mainly associated with weather and geographical distance among sites. Also, fruit production for a given year was less variable among sites during warm and dry springs (negative spring NAO phases). Our results identify the Moran effect as the most likely mechanism for synchronisation of fruit production at large geographical scales and the possibility that pollen availability plays a role in synchronising fruit production at local scales. Our results highlight the influence of the NAO on the patterns of fruit production across western Europe.

Keywords: synchrony, seeds, weather lagged effects, tree reproduction 


\section{Introduction}

47 Production of fruit and seeds is an essential step in the life cycle of plants that allows individuals to transmit their genes to the next generation and to colonise new territories. Reproduction, however, has important implications beyond the plant itself, especially if it concerns the key species of a community: production of fruit can alter entire ecosystems by producing cascading effects throughout food webs (Elkinton et al. 1996, Ostfeld and Keesing 2000), even affecting the transmission of diseases such as Lyme disease to humans (Ostfeld 1997). Different patterns of fruit production can thus have a range of different consequences for ecosystems.

Two of the most studied hypotheses attempting to account for interannual variability in fruit production are the resource matching and the pollination efficiency hypotheses. The mechanistic resource matching hypothesis (Norton and Kelly 1988, Sork et al. 1993, Kelly and Sork 2002) suggests that plants produce fruit as a direct response to the available resources (Table 1). The pollination efficiency hypothesis (Norton and Kelly 1988, Smith et al. 1990, Koenig and Ashley 2003), however, states that synchronised and intermittent flowering increases the success of pollination in wind-pollinated species because it ensures a high rate of successful pollination during years of extensive flowering (Table 1). Both hypotheses can be indirectly related to meteorological variability, because weather can influence both the acquisition of tree resources (e.g. by increased photosynthesis) and environmental conditions associated with effective pollination.

Similarly to interannual variability, synchrony in fruit production has also mostly been explained by two hypotheses. Moran's theory (Moran 1953, Ranta et al. 1997) states that synchrony in fruit production is controlled by synchrony in meteorological conditions, which prompt trees to divert resources into reproduction or, mechanistically, to producing more fruit when weather is favourable for acquiring more resources (Table 1). Because meteorological conditions can also be spatially synchronous (Koenig 2002), the Moran effect has also been hypothesised to synchronise of fruit production over large geographical areas (Koenig and Knops 2013). The pollen coupling hypothesis (Satake and Iwasa 2002), however, suggests that the available pollen from neighbouring trees can generate synchrony in fruit production among individuals 
by interacting with the resources available to the trees (Table 1, i.e., extensive maturation of female flowers after a massive pollinating event (when enough pollen is available) would deplete the resources of all trees at the same time, increasing synchronisation of fruit production within the population among years in the long run).

Most studies that have tested these hypotheses have based their conclusions on the relationship between meteorological conditions and interannual variability and synchrony in fruit production, due to the importance of meteorological variability to plant productivity (Sork et al. 1993, Fernández-Martínez et al. 2012, Koenig and Knops 2013). Recent studies have highlighted the possible role of temperature as a meteorological cue (Kelly et al. 2013, Kon and Saito 2015), although another study has suggested that temperature likely acts mainly as a proximal cause for the prediction of fruit crop size (Pearse et al. 2014). In any case, temperature variability would also explain synchrony in fruit production, because changes in temperature occur at wide geographical scales (Koenig 2002). Other meteorological variables (e.g., precipitation or water stress), however, could also be used as meteorological predictors of interannual variability and synchrony in fruit production (Sork et al. 1993, García-Mozo et al. 2007, Espelta et al. 2008, Fernández-Martínez et al. 2012).

Weather at continental scales is mostly driven by general patterns of atmospheric circulation. Climatic teleconnections can influence weather strongly over very large areas. The El Niño/Southern Oscillation affects the weather of the entire planet (Grove 1998, NOAA 2012), and the North Atlantic Oscillation (NAO, the dipole connecting the Icelandic low with the Azores high) strongly affects the Atlantic basins of Europe and North America (Hurrell et al. 2002, 2003). Ecosystems may accordingly also be affected by teleconnections (Straile 2002, Menzel et al. 2005, Martínez-Jauregui et al. 2009, Hódar et al. 2011), and some studies have suggested that teleconnection indices often predict ecological processes better than local weather (Ottersen et al. 2001, Stenseth et al. 2003, Hallett et al. 2004) because they aggregate meteorological conditions over large spatial scales. The NAO index may thus be an excellent meteorological cue. Nonetheless, the role of such climatic teleconnections, has rarely been explored in studies focused on fruit production (but see Wright et al. (1999)). Additionally, most of the published literature exploring the effects of the NAO on ecosystems has focused on the values of the index in winter (Ottersen et al. 2001), which can limit usefulness of the 
approach, because different biological processes might be influenced by weather in different seasons.

Fruit production in some species has been strongly correlated with weather in warm seasons (Sork et al. 1993, Fernández-Martínez et al. 2012, 2015, Kelly et al. 2013, Pearse et al. 2014), for which the winter NAO (NAOw) may have little influence. Tree species with contrasting leaf habits (evergreen and deciduous) may be sensitive to meteorological conditions during different seasons. Winter-deciduous species must accumulate enough resources prior to winter for spring leaf unfolding and flowering, so autumn weather likely has some influence on next year's productivity. Winter meteorological variability, however, may play a role in determining plant productivity during the next year, because evergreen species preserve their leaves during the winter. Exploring the effects of the NAO index for other seasons may also provide interesting results and even improve the prediction capacity of the models.

We tested the ability of seasonal NAO indices to predict interannual variability in fruit production by constructing statistical models, including local meteorological (temperature and precipitation) variables and NAO indices for the previous autumn, winter, spring, and summer seasons, using data from 76 forests of Abies alba, Fagus sylvatica, Picea abies, Pseudotsuga menziesii, Quercus petraea, and Q. robur distributed across Europe. We also identified the environmental variables that could account for synchrony in fruit production among forests within species. Finally, we discuss the plausibility of various hypotheses addressing interannual variability and synchrony in fruit production based on our statistical results.

\section{Materials and methods}

\subsection{Data collection}

\subsubsection{Data for litterfall and foliar nutrient concentration}

We downloaded litterfall data from the ICP Forests database (International Co-operative Programme on Assessment and Monitoring of Air Pollution Effects on Forest, operated under the UNECE Convention on Long-range Transboundary Air Pollution, http://icp-forests.net/). The dataset contained information about fruit-production for several forest tree species in Europe for 2002-2010. Fruit litterfall was totalled per plot and year. Because the original data for litterfall was available in units of $g$ of dry weight $\mathrm{m}^{-2} \mathrm{y}^{-1}$, we used fruit carbon (C) content 
134 data (provided by the same database) to calculate litterfall in units of $\mathrm{g} \mathrm{C} \mathrm{m}^{-2} \mathrm{y}^{-1}$ (as fruit net 135 primary production [NPP]). Although data from 210 forests were available in the database we used only data from 76 single-species forests with time series records of five or more years to ensure that we had reliable records of single-species fruit production suitable for analysis of interannual variation. These selected forests consisted of A. alba, F. sylvatica, P. abies, Ps. menziesii, $Q$. petraea, and $Q$. robur and were distributed over France, Germany, and Luxemburg (Figure 1).

\subsubsection{Meteorological data}

We extracted meteorological time series for our forests from the interpolated meteorological data of the MARS unit AGRI4CAST/JRC (http://agri4cast.jrc.ec.europa.eu/), with a resolution of $0.25 \times 0.25$ degrees (latitude, longitude). This database provided monthly mean temperatures and total precipitation for 2001 to 2010. We also downloaded the NAO index time series for daily data, covering the period from 1 January 1950 to 31 December 2014, from the Climate Prediction Center of the National Weather Service (NOAA, http://www.cpc.ncep.noaa.gov/). We then calculated the seasonal NAO indices, temperatures, and precipitation for winter, spring, summer, and autumn. We calculated the winter values as the average (for temperature and NAO) or the sum (for precipitation) of January, February, and March; spring comprised the months of April, May, and June; summer comprised the months of July, August, and September, and autumn comprised the months of October, November, and December. The seasonal NAO indices were standardised $\left(\left[x_{i}-\bar{x}\right] \cdot S D^{-1}\right)$ for the period 1950-2014.

\subsection{Data analyses}

\subsubsection{Interannual variability of fruit production}

Table 2 summarizes the analyses performed in this study. We evaluated the influence of the seasonal NAO indices on local seasonal weather (temperature and precipitation) by fitting generalised linear mixed models (GLMMs) with the nlme R package (Pinheiro et al. 2013), using restricted maximum likelihood (REML) and a Gaussian distribution, where the site was the random factor and the seasonal NAO indices were related to seasonal temperature and precipitation. 
We assessed the correlations between the seasonal NAO indices and fruit production using Spearman correlations for each site between the seasonal NAO indices and fruit-production time series. We then calculated the average correlations between fruit production and the seasonal NAO indices per species. We next fitted the GLMMs using REML and a Gaussian distribution, where the site was the random factor. We accounted for the effect of the previous fruit crop by also including in the models an autoregressive term for lag 1 (ARMA [1,0], crop year i crop year i-1). Saturated models (models including all possible predictors) predicting interannual variability in fruit production included temperature, precipitation, and the NAO indices for the autumn, winter, spring, and summer previous to fruit ripening (e.g. fruit crop year $\mathrm{i} \sim$ autumn temperature year $\mathrm{i}-1+$ winter temperature year $\mathrm{i}+\ldots)$. The variables for each model were selected using the dredge function in the MuMin R package (Barton 2015) using the best subset model selection and using the Bayesian Information Criterion (BIC) as the measure of model adjustment (the best model had the lowest BIC). We also calculated the variance explained by the fixed factors (marginal variance, $R^{2} \mathrm{~m}$ ) and by the entire model (conditional variance, $R^{2}$ c) for the final models using the methodology proposed by Nakagawa \& Schielzeth (2013), also implemented in the MuMln R package (Barton 2015) by the function r.squaredGLMM. The difference between the marginal and conditional variances explained was the variance explained by the random factors. We assessed the importance of the predictors within the models by calculating their $\triangle \mathrm{BICs}$ as the difference between the BIC of the final model and the BIC of the model without the predictor of interest. The higher the $\triangle \mathrm{BIC}$, the larger the importance of the predictor within the model. Fruit NPP was log-transformed to meet the assumptions of normality and heteroscedasticity in the model residuals. We also used mixed models with random slopes to test the effect of the seasonal NAO indices on temperature and precipitation, using site as the random factor.

Relationships between fruit production and meteorological variables that can be associated either with successful pollination (supporting the pollination efficiency hypothesis) or higher tree productivity (indirectly supporting the resource matching hypothesis) would indicate an effect of weather on fruit production by proximal causes. If the relationship between weather and fruit production cannot be correlated with well-established physiological responses (e.g., warm and wet conditions normally increase tree productivity [Fernández-Martínez et al. 2014]), the results may be supporting the role of weather as a cue for fruit production. 


\subsubsection{Synchrony of fruit production among forests}

We first tested whether higher variability in meteorological conditions among sites was associated with higher variability in fruit production for a given year. We calculated the annual coefficient of variation ( $\mathrm{CV}=$ standard deviation $\cdot$ mean $^{-1}$ ) amongst sites of seasonal (winter, spring, summer, and autumn) temperature and precipitation and of annual fruit production for each species for each of the years with records for more than five forests per species. We then used GLMMs with species as the random factor to determine the significance of the association between the CVs for annual fruit production and weather among sites and the seasonal NAO indices. Positive associations between the CVs for annual fruit production and weather would further support the Moran-effect hypothesis, and no association would indicate that other mechanisms, such as pollen coupling, might be involved in synchronising fruit production.

We then calculated the degree of synchrony in fruit production among all sites using Spearman's correlations $(\rho)$ for all sites with data for at least the same five years, and calculated the mean correlation of fruit production per species and among species. We then identified the main controls of synchrony in fruit production among forests within species by first calculating the synchrony $(\rho)$ for weather (seasonal temperatures and precipitation) among forests of the same species, and used linear models to identify the relationships of synchrony in weather and synchrony in fruit production with geographical distance. The Moran effect would be supported if the slope between distance and synchrony in seasonal temperature or precipitation among sites was as high as or higher than the slope between distance and synchrony in fruit production among sites (similar slopes using a $t$-test, $P>0.05$ ). If the slopes differed or fruit production was not spatially synchronous among forests, the results would indicate that the synchrony was at more local scales and thus provide indirect evidence supporting the pollen coupling hypothesis(Table 1).

We constructed linear models in which the response variable was the synchrony $(\rho)$ of fruit production between two forests and the predictor variables were the geographical distance between sites and the correlation between winter, spring, summer, and autumn temperatures and precipitation for the two forests. We next selected the model using the dredge function in the MuMin R package (Barton 2015) using the best subset model selection and using BIC as the measure of model adjustment. The best model was then assumed to have the lowest BIC 
225 with all variables significant at the 0.05 level and with no negative coefficients for the 226 meteorological variables (because negative associations between synchrony in fruit production 227 and in meteorological variables would be nonsensical). The percentage of variance explained 228 by the predictors was assessed using the proportional marginal variance decomposition metric 229 pmvd from the relaimpo R package (Grömping 2007).

230 Similar to the results for interannual variability, significant relationships between synchrony in 231 fruit production and synchrony in meteorological variables from periods potentially associated 232 with tree productivity would indicate the Moran effect as a result of proximal causes of weather 233 on fruit production. If meteorological variables associated with synchrony in fruit production 234 were also be associated with spring conditions, during pollination, the pollen coupling 235 hypothesis would be supported (Table 1). If meteorological predictors of fruit synchrony could 236 not be associated with the pollinating period nor with higher tree productivity, the results would 237 support the Moran effect with weather acting as a cue for the trees.

238 We used the visreg $\mathrm{R}$ package (Breheny and Burchett 2015) to visualise the regression 239 models using partial plots. All data treatments and analyses were conducted using R (R Core 240 Team 2015).

241 3. Results

242 3.1. Effects of seasonal NAO on local weather

243 The seasonal NAO indices were correlated with the weather at our sites (Figure 2). Positive $244 \mathrm{NAO}_{w}$ phases were correlated with warm and wet winters, and positive spring NAO (NAO sp) 245 phases were correlated with warm and dry weather. Positive summer and autumn NAOs $246\left(\mathrm{NAO}_{\mathrm{sm}}\right.$ and $\mathrm{NAO}_{\mathrm{a}}$, respectively) were correlated with cold and dry weather. The seasonal 247 NAO indices, however, were not significantly correlated, either during the study period (2002248 2010) or for a longer period (1950-2014). The correlations among seasonal NAO phases were 249 generally small and not significant.

\subsection{Interannual variability of fruit production}

251 Both changes in weather and the seasonal NAO indices were individually correlated with fruit 252 production for all tree species (Table 3). Fruit crop size in both Quercus species and $A$. alba 
was negatively associated with the NAO phase of the autumn prior to fruit ripening, whereas fruit production and $\mathrm{NAO}_{w}$ were strongly positively correlated for the three coniferous species. Fruit crop size was positively associated with $\mathrm{NAO}_{\text {sp }}$ in $A$. alba, F. sylvatica, and Q. robur and with $\mathrm{NAO}_{\text {sm }}$ in $P$. abies and $F$. sylvatica.

GLMM models predicting fruit crop size using local seasonal weather and the seasonal NAO indices also identified a relevant role of the NAO phases in predicting interannual variability in fruit production (Table 4). In addition, the seasonal NAO variables were usually the most important variables identified by $\triangle \mathrm{BIC}$. The univariate analysis correlated fruit crop size in $A$. alba negatively with $\mathrm{NAO}_{w}$ and positively with $\mathrm{NAO}_{\text {sp. }}$. The model also identified a significant negative relationship between winter precipitation and fruit production. Based on $\triangle \mathrm{BIC}$, both NAO variables were similarly important for predicting variability in fruit production and were clearly more important than winter precipitation. Large fruit crops in $P$. abies were associated with rainy winters, dry springs, and dry $\left(\mathrm{NAO}_{\mathrm{sm}^{+}}\right.$, in positive phase) warm summers, with $\mathrm{NAO}_{\mathrm{sp}}$ and winter precipitation the most important variables. Fruit crop size for $P$. menziesii was positively correlated with cold and dry autumns $\left(\mathrm{NAO}_{2}{ }^{+}\right)$, warm and wet winters $\left(\mathrm{NAO}^{-}\right.$, in negative phase), and warm springs, being $\mathrm{NAO}_{a}$ the most important variable in the model according to $\triangle \mathrm{BIC}$. Fruit production in $F$. sylvatica, as for $P$. abies, was positively correlated with cold and dry autumns $\left(\mathrm{NAO}_{\mathrm{a}}{ }^{+}\right.$and temperature) but also with dry and warm springs (NAOsp) and dry summers. Conversely, Q. petraea and Q. robur produced larger fruit crops after warm and wet autumns. Fruit production in $Q$. robur was also positively correlated with wet summers and cold winters. The best model predicting interannual variability for $Q$. robur did not identify NAO as a significant predictor, but the next model (differing only by $0.76 \mathrm{BIC}$ units from the best model in Table 4) included $\mathrm{NAO}_{a}$ instead of winter temperature. Seasonal NAO indices were thus able to predict the interannual variability of fruit production moderately well for all tree species.

\subsection{Patterns of intra- and interspecific synchrony in fruit production}

$\mathrm{NAO}_{\text {sp }}$ was the most highly correlated variable explaining the variability in the CVs for annual fruit production among species (Figure 3). The CV for annual fruit production was negatively correlated with $\mathrm{NAO}_{\text {sp }}$ for all species except $P$. menziesii, and the relationship was statistically significant for $F$. sylvatica, $Q$. robur, and $P$. abies $(P=0.005,0.012$, and 0.041 , respectively). 
F. sylvatica was the most synchronised species producing fruit, with a mean synchrony among sites of $0.60 \pm 0.02$. In contrast, synchrony in fruit production among sites was not statistically significant for P. menziesii (Table 5, a). A. alba, P. abies, Q. petraea, and Q. robur also had important synchronies in fruit production. Synchrony in fruit production, however, was significantly lower than synchrony in most of the seasonal meteorological variables (temperature and precipitation) for most of the species (Table 5, a). Fruit production in all species (except $P$. menziesii) showed strong spatial correlations with meteorological synchrony (Table 5, b), but the synchrony of fruit production was not strongly spatially dependent using univariate regressions. The slope between synchrony in fruit production and distance between plots was statistically significant only for $Q$. robur, and the slope coefficients were very close to zero for some species such as $F$. sylvatica and $Q$. petraea (Table 5, b) and were significantly different from most of the distance $\times$ weather correlation slopes ( $t$-tests, $P<0.05)$. The slopes between fruit production and distance for $A$. alba, $P$. abies, $P$. menziesii, and $Q$. robur did not differ significantly ( $t$-tests, $P>0.05$ ) from those for most of the weather $\times$ distance relationships.

Amongst species, synchrony in fruit production decreased considerably compared to withinspecies synchrony, and some combinations were even significantly negatively correlated, such as F. sylvatica versus $P$. menziesii and $Q$. petraea (Table 6). Synchrony of fruit production amongst sites was generally similar between leaf types (Table 6; $t$-test, $P>0.05$ ).

Our models correlating synchrony in fruit production with synchrony in meteorological variables indicated that seasonal weather had a limited impact on intraspecific synchrony amongst sites (Table 7). Synchrony of meteorological conditions between sites was only a significant driver of synchrony in fruit production for A. alba (autumn temperature), F. sylvatica (winter precipitation), and $Q$. petraea (summer precipitation). The only significant relationship for synchrony in fruit production for $Q$. robur was a negative relationship with distance between sites, similar to the results of the univariate analyses (Table 5). Synchrony in fruit production for $P$. abies was not significantly correlated with synchrony in meteorological conditions.

\section{Discussion}

\subsection{Teleconnection indices as biological predictors}


312 Our results fully support the hypothesis that teleconnection indices are better correlated with 313 biological processes than local weather (Ottersen et al. 2001, Hallett et al. 2004). Fruit 314 production of all species that we considered had statistically significant relationships with 315 seasonal NAO indices (Figure 3, Tables 3 and 4), highlighting the importance of the NAO as 316 a driver of ecological processes through effects on meteorological conditions at large spatial 317 scales (Figure 2). These results are thought to emerge because organisms do not respond to 318 single environmental variables but to a combination of variables. The NAO indices are thus 319 good predictors of weather packages (i.e. temperature, precipitation, humidity, wind, radiation, 320 or pressure), reducing spatiotemporal variability in meteorological conditions into a single index 321 (Stenseth et al. 2003) influencing weather over continental scales. The utility of the NAO (and 322 other teleconnection indices) for characterizing weather packages influencing very large 323 geographical scales make them suitable candidate variables for testing the Moran effect.

\subsection{Controls of interannual variability of fruit production}

325 Our results highlighted a contrasting effect of seasonal NAO indices on fruit production for coniferous and broadleaved species: cone crops in coniferous species were mainly negatively correlated with $\mathrm{NAO}_{w}$ (i.e., associated to dry and cool winters), but fruit production in broadleaved species was positively correlated with $\mathrm{NAO}_{\mathrm{sp}}$ (associated with warm and dry springs) and negatively correlated with $\mathrm{NAO}_{a}$ (associated with warm and wet autumns) (Tables 3 and 4). Nonetheless, these relationships could be altered by local weather (e.g., the positive correlation between winter precipitation and fruit production for $P$. abies in Table 4). These differences, in part, reflect differences in the effect of leaf characteristics on when weather influences fruit production. Coniferous species in our study were all evergreen (main effect during winter) and the broadleaved species were all deciduous (main effect during spring).

336 Cold winters may delay the growing season for evergreen species and thus the onset of 337 flowering (Frenguelli and Bricchi 1998, García-Mozo et al. 2002, Stöckli and Vidale 2004). 338 Delays in pollinating periods due to cold meteorological conditions have been previously 339 reported to positively affect fruit production in the evergreen Q. ilex (Fernández-Martínez et al. 2012). Additionally, cold winter weather may meet the chilling requirements for conifers to reach complete dormancy (Clancy et al. 1995), as is needed to survive unfavourable environmental conditions. In contrast, higher winter temperatures might entail higher metabolic 
costs for trees, reducing the amount of reserves available to invest in reproduction. This reasoning is in line with the resource matching hypothesis, i.e., trees would produce fruit as a response to the available resources (Table 1).

Dry and warm spring weather (during pollination), however, can facilitate pollen dispersal, because pollen release to the atmosphere increases with temperature and precipitation removes the pollen (García-mozo et al. 2006, Fernández-Martínez et al. 2012, Kasprzyk et al. 2014). We thus suggest that fruit production in deciduous broadleaved species (and A. alba, see Tables 3 and 4) was positively associated with the NAOsp phase because dry and warm weather facilitates pollen release and therefore the fertilisation of female flowers, supporting the pollination efficiency hypothesis (Table 1).

Fruit crop size for $Q$. petraea, (and also Q. robur and A. alba, see Table 3) was correlated with warm and wet autumns. Leaf senescence and the start of dormancy is delayed during warm and wet autumns $\left(\mathrm{NAO}_{\mathrm{a}}{ }^{-}\right)$because of the strong control that temperature exerts on them (Vitasse et al. 2009, Estiarte and Peñuelas 2015). Delayed leaf senescence extends the growing period, which allows trees to accumulate resources immediately after most of the fruit is matured. This additional acquisition of resources (Euskirchen et al. 2006) and tree growth at the end of the growing season could be spent during the next spring to enable more intense flowering (Fernández-Martínez et al. 2015). This mechanism would be in line with the resource matching hypothesis (Table 1).

Dry and cool summer weather $\left(\mathrm{NAO}_{s m}{ }^{+}\right)$increased fruit crop size in $P$. abies and $F$. sylvatica (Table 3). Because species characteristic of colder and wetter environments are generally more sensitive to changes in temperature than in water availability (Fernández-Martínez et al. 2014), high summer temperatures may lead to photoinhibition and stomatal closure and thereby reduce photosynthetic capacity, constraining resources available to allocate to ripening fruit. This reasoning mechanism potentially driven by effects of the $\mathrm{NAO}_{\text {sm }}$ on fruit production provide further indirect evidence supporting the resource matching hypothesis for $P$. abies and F. sylvatica (Table 1).

In short, our results generally indicated proximal causes (weather correlated with increased productivity or better pollinating conditions), likely driven by the NAO, as amongst the most plausible mechanisms explaining interannual variability in fruit production. They also indirectly 
suggest that the resource matching and pollination efficiency hypotheses may actually function together (Table 1), especially for the broadleaved species studied here, as potential drivers of interannual variability in fruit production in European forests. The different mechanisms proposed by each of these two hypotheses are likely required to a certain degree to explain the large interannual variability in fruit crops and its synchrony. The relative importance of each mechanism will surely depend on the species under study and on the site characteristics (Fernández-Martínez et al. 2012). In addition, the considerable variance explained by the models accounting for interannual variability in fruit production suggests that meteorological variability should be one of the most important factors driving interannual variability and synchrony in fruit production (Fernández-Martínez et al. 2015)

\subsection{Controls of synchrony of fruit production}

Whether synchrony in fruit production is due to the Moran effect or pollen coupling is usually hard to determine, because both hypotheses generate similar patterns of spatial synchrony and are not mutually exclusive (Liebhold et al. 2004, Koenig and Knops 2013). Some predictions of both hypotheses, however, can help to distinguish between them. Synchrony in fruit production due to pollen coupling should not extend more than a few hundred kilometres at most, and the Moran effect can easily reach hundreds and even thousands of kilometres (Koenig and Knops 2013). According to this prediction, our results suggest that the Moran effect is responsible for the synchrony in fruit production among European forests, some separated by hundreds of kilometres. This inference, however, cannot completley dismiss the pollen coupling hypothesis, because our database consisted of forests and not individual trees, so pollen coupling could still be acting to amplify synchrony at the local scale.

The anti-synchrony in fruit production between $F$. sylvatica and $Q$. petraea (Table 6), two potentially co-existing species, suggests a strategy for avoiding large fruit crops in the same years. Although such a strategy would be contrary to the predation satiation hypothesis (Silvertown 1980, Espelta et al. 2008) but could reduce interspecific interference in pollination, because most of the pollen reaching female flowers would be from the same species in years of high intraspecifically synchronous reproduction. This hypothetical mechanism would tend to support the hypothesis that fruit production is synchronized by pollen coupling. Nonetheless, synchrony between non-hybridising species cannot occur by pollen coupling, and we found significant synchrony amongst species that do not hybridise (Table 6). This result further 
404 supports the synchronization of reproduction through the Moran effect, especially when 405 combined with the results from our models suggesting that the seasonal NAO indices are 406 common drivers of interannual variability.

407 The Moran effect also predicts that distance between sites will be similarly related to both 408 synchrony in fruit production and meteorological variables (Koenig and Knops 2013). Our 409 results corroborate with this prediction for $A$. alba, $P$. abies, $P$. menziesii, and $Q$. robur, thus 410 further supporting the Moran effect as an underlying cause of the patterns we have identified. 411 Our findings for F. sylvatica and Q. petraea, however, do not support this prediction, because 412 synchrony in fruit production for these species and meteorological variables were differently 413 related to distance (Table 5). Interannual variability in fruit production for $F$. sylvatica was also 414 linked to dry and warm spring weather, favouring pollen dispersal, so pollen coupling likely also 415 plays a role synchronising fruit production in these forests and possibly also in Q. petraea 416 forests given the similar relation of synchrony in fruit production and meteorological variables 417 with distance (Table 1). Weather also likely plays a role in synchronising fruit crop sizes 418 amongst sites because synchrony in meteorological conditions was correlated with synchrony 419 in fruit production for A. alba, F. sylvatica, and Q. petraea. Our results must be interpreted with 420 care, however, because none of the variables involved in predicting synchrony in fruit 421 production also predicted interannual variability in fruit production and because the synchrony 422 models explained only a small amount of the variance. Nonetheless, the NAO is clearly 423 partially responsible for interannual variability in meteorological conditions over western 424 Europe, and so we infer that 1) the NAO acts as a synchronising agent among sites and 2) the 425 Moran effect is probably the main factor synchronising the fruit production of forests in western 426 Europe (Table 1).

427 Both the Moran effect and the pollen coupling hypotheses may thus play a role in 428 synchronising fruit production, but at different levels. Whereas the Moran effect is apparent at 429 continental scales, pollen coupling may be restricted to local or nearby regional environments. 430 Moreover, according to our results, evidence for the Moran effect seems to apply to more 431 systems than does evidence for pollen coupling.

432 Our results generally highlight that weather packages, such as the NAO index, can improve 433 prediction of ecological processes at wide geographical scales, which is particularly useful for 434 testing the explanatory power of the Moran effect in particular situations. Since weather is 
435 likely to affect tree resources and enable favourable meteorological conditions for pollination, 436 we suggest that the synchronising effect of weather was more likely to be due to proximal 437 causes driving interannual variability rather than the effect of weather as a cue for tree 438 reproduction. 
441 This research was supported by the European Research Council Synergy grant ERC-2013442 SyG 610028-IMBALANCE-P, the Spanish Government grant CGL2013-48074-P, and the 443 Catalan Government projects SGR 2014-274 and FI-2013. SV is a Postdoctoral Fellow of the 444 Research Foundation - Flanders (FWO). We appreciate the financial support of the GHG445 Europe project. We also thank ICP Forests and all those contributing investigators who 446 provided data. Finally, we thank John R. Spence and two anonymous reviewers for helping us improve our manuscript.

\section{References}

Barton, K. 2015. MuMIn: Multi-model inference. R package version 1.17.1. http://CRAN.Rproject.org/package $=$ MuMln. in press.

Breheny, P. and Burchett, W. 2015. Visualization of Regression Models Using visreg, R package version 2.2-0. in press.

Clancy, K. M. et al. 1995. Ecophysiology of Coniferous Forests. - Elsevier.

Elkinton, J. S. et al. 1996. Interactions Among Gypsy Moths, White-footed Mice, and Acorns. - Ecology 77: 2332-2342.

Espelta, J. M. et al. 2008. Masting Mediated by Summer Drought Reduces Acorn Predation in Mediterranean Oak Forests. - Ecology 89: 805-817.

Estiarte, M. and Peñuelas, J. 2015. Alteration of the phenology of leaf senescence and fall in winter deciduous species by climate change: effects on nutrient proficiency. - Glob. Chang. Biol. 21: 1005-1017.

Euskirchen, E. S. et al. 2006. Importance of recent shifts in soil thermal dynamics on growing season length, productivity, and carbon sequestration in terrestrial high-latitude ecosystems. - Glob. Chang. Biol. 12: 731-750.

Fernández-Martínez, M. et al. 2012. Masting in oaks: Disentangling the effect of flowering phenology, airborne pollen load and drought. - Acta Oecologica 43: 51-59.

Fernández-Martínez, M. et al. 2014. Spatial variability and controls over biomass stocks, carbon fluxes and resource-use efficiencies in forest ecosystems. - Trees, Struct. Funct. 28: 597-611.

Fernández-Martínez, M. et al. 2015. Temporal trends in the enhanced vegetation index and spring weather predict seed production in Mediterranean oaks. - Plant Ecol. 216: 1061-1072.

Frenguelli, G. and Bricchi, E. 1998. The use of the pheno-climatic model for forecasting the pollination of some arboreal taxa. - Aerobiologia (Bologna). 14: 39-44.

García-Mozo, H. et al. 2002. Modelling start of oak pollen season in different climatic zones in Spain. Agric. For. Meteorol. 110: 247-257.

García-mozo, H. et al. 2006. Quercus pollen season dynamics in the lberian Peninsula: response to meteorological parameters and possible consequences of climate change. - Ann. Agric. Environ. Med. 13: 209-224. 
García-Mozo, H. et al. 2007. Influence of pollen emission and weather-related factors on variations in holm-oak (Quercus ilex subsp. ballota) acorn production. - Environ. Exp. Bot. 61: 35-40.

Grömping, U. 2007. Estimators of Relative Importance in Linear Regression Based on Variance Decomposition. - Am. Stat. 61: 139-147.

Grove, R. H. 1998. Global impact of the 1789-93 El Nino. 393: 318-319.

Hallett, T. B. et al. 2004. Why large-scale climate indices seem to predict ecological processes better than local weather. - Nature 430: 71-75.

Hódar, J. a. et al. 2011. Climate change and the incidence of a forest pest in Mediterranean ecosystems: can the North Atlantic Oscillation be used as a predictor? - Clim. Change 113: 699711.

Hurrell, J. et al. 2002. Climatic variability over the North Atlantic. - Int. Geophys.: 1-22.

Hurrell, J. W. et al. 2003. An Overview of the North Atlantic Oscillation. - North Atl. Oscil. Clim. Significance Environ. Impact 134: 263.

Kasprzyk, I. et al. 2014. Relationships among weather parameters, airborne pollen and seed crops of Fagus and Quercus in Poland. - Agric. For. Meteorol. 197: 111-122.

Kelly, D. and Sork, V. L. 2002. Mast seeding in perennial plants: why, how, where? - Annu. Rev. Ecol. Syst. 33: 427-447.

Kelly, D. et al. 2013. Of mast and mean: differential-temperature cue makes mast seeding insensitive to climate change. - Ecol. Lett. 16: 90-8.

Koenig, W. D. 2002. Global patterns of environmental synchrony and the Moran effect. - Ecography (Cop.). 25: 283-288.

Koenig, W. D. and Ashley, M. V. 2003. Is pollen limited? The answer is blowin' in the wind. - Trends Ecol. Evol. 18: 157-159.

Koenig, W. D. and Knops, J. M. H. 2013. Large-scale spatial synchrony and cross-synchrony in acorn production by two California oaks. - Ecology 94: 83-93.

Kon, H. and Saito, H. 2015. Test of the temperature difference model predicting masting behavior. Can. J. For. Res.: 150901143607000.

Liebhold, A. et al. 2004. Within-• population spatial synchrony in mast seeding of North American oaks. - Oikos 104: 156-164.

Martínez-Jauregui, M. et al. 2009. Are local weather, NDVI and NAO consistent determinants of red deer weight across three contrasting European countries? - Glob. Chang. Biol. 15: 1727-1738.

Menzel, A. et al. 2005. "SSW to NNE" - North Atlantic Oscillation affects the progress of seasons across Europe. - Glob. Chang. Biol. 11: 909-918.

Moran, P. 1953. The statistical analysis of the Canadian Lynx cycle. - Aust. J. Zool. 1: 291.

Nakagawa, S. and Schielzeth, H. 2013. A general and simple method for obtaining $R 2$ from generalized linear mixed-effects models (RB O'Hara, Ed.). - Methods Ecol. Evol. 4: 133-142.

NOAA 2012. State of the Climate: Global Analysis for Annual 2012.

Norton, D. A. and Kelly, D. 1988. Mast Seeding Over 33 Years by Dacrydium cupressinum Lamb. (rimu) (Podocarpaceae) in New Zealand: The Importance of Economies of Scale. - Funct. Ecol. 2: 399-408.

Ostfeld, R. S. 1997. The ecology of Lyme-disease risk. - Am. Sci. 85: 338-346. 
Ostfeld, R. and Keesing, F. 2000. Pulsed resources and community dynamics of consumers in terrestrial ecosystems. - Trends Ecol. Evol. 15: 232-237.

Ottersen, G. et al. 2001. Ecological effects of the North Atlantic Oscillation. - Oecologia 128: 1-14.

Pearse, I. S. et al. 2014. Cues versus proximate drivers: testing the mechanism behind masting behavior. - Oikos 123: 179-184.

Pinheiro, J. et al. 2013. nlme: Linear and Nonlinear Mixed Effects Models. in press.

R Core Team 2015. R: A Language and Environment for Statistical Computing. in press.

Ranta, E. et al. 1997. The Moran effect and synchrony in population dynamics. - Oikos in press.

Satake, A. and Iwasa, Y. 2002. The Synchronized and Intermittent Reproduction of Forest Trees Is Mediated by the Moran Effect, Only in Association with Pollen Coupling. - J. Ecol. 90: 830-838.

Silvertown, J. W. 1980. The evolutionary ecology of mast seeding in trees. - Biol. J. Linn. Soc. 14: 235250.

Smith, C. C. et al. 1990. The Advantage of Mast Years for Wind Pollination. - Am. Nat. 136: 154.

Sork, V. L. et al. 1993. Ecology of mast-fruiting in three species of North American deciduous oaks. Ecology 74: 528-541.

Stenseth, N. C. et al. 2003. Studying climate effects on ecology through the use of climate indices: the North Atlantic Oscillation, El Niño Southern Oscillation and beyond. - Proc. Biol. Sci. 270: 208796.

Stöckli, R. and Vidale, P. L. 2004. European plant phenology and climate as seen in a 20-year AVHRR land-surface parameter dataset. - Int. J. Remote Sens. 25: 3303-3330.

Straile, D. 2002. North Atlantic Oscillation synchronizes food-web interactions in central European lakes. - Proc. Biol. Sci. 269: 391-5.

Vitasse, Y. et al. 2009. Responses of canopy duration to temperature changes in four temperate tree species: relative contributions of spring and autumn leaf phenology. - Oecologia 161: 187-198.

Wright, S. J. et al. 1999. The el Niño southern oscillation, variable fruit production, and famine in a tropical forest. - Ecology 80: 1632-1647. 
546 Figure captions

547 Figure 1: Map showing the sites used in this study. The sites were located throughout France, 548 Germany, and Luxembourg.

549 Figure 2: Relationships between the seasonal North Atlantic Oscillation (NAO) indices and 550 weather for 2002-2010. Positive (+) and negative (-) symbols after NAO indicate positive and 551 negative phases of the index. Values are $\beta$ weights calculated using generalised linear mixed 552 models with random slopes. All coefficients were significant at the 0.001 level.

553 Figure 3: a) Relationships between the CV of annual fruit production and the spring NAO 554 index for the six species. Thick lines indicate significant relationships at the 0.05 level. b) 555 Partial residuals plot showing the average relationship between the annual CV of fruit 556 production and the spring NAO index amongst species using generalised linear mixed models. 
Figure 1

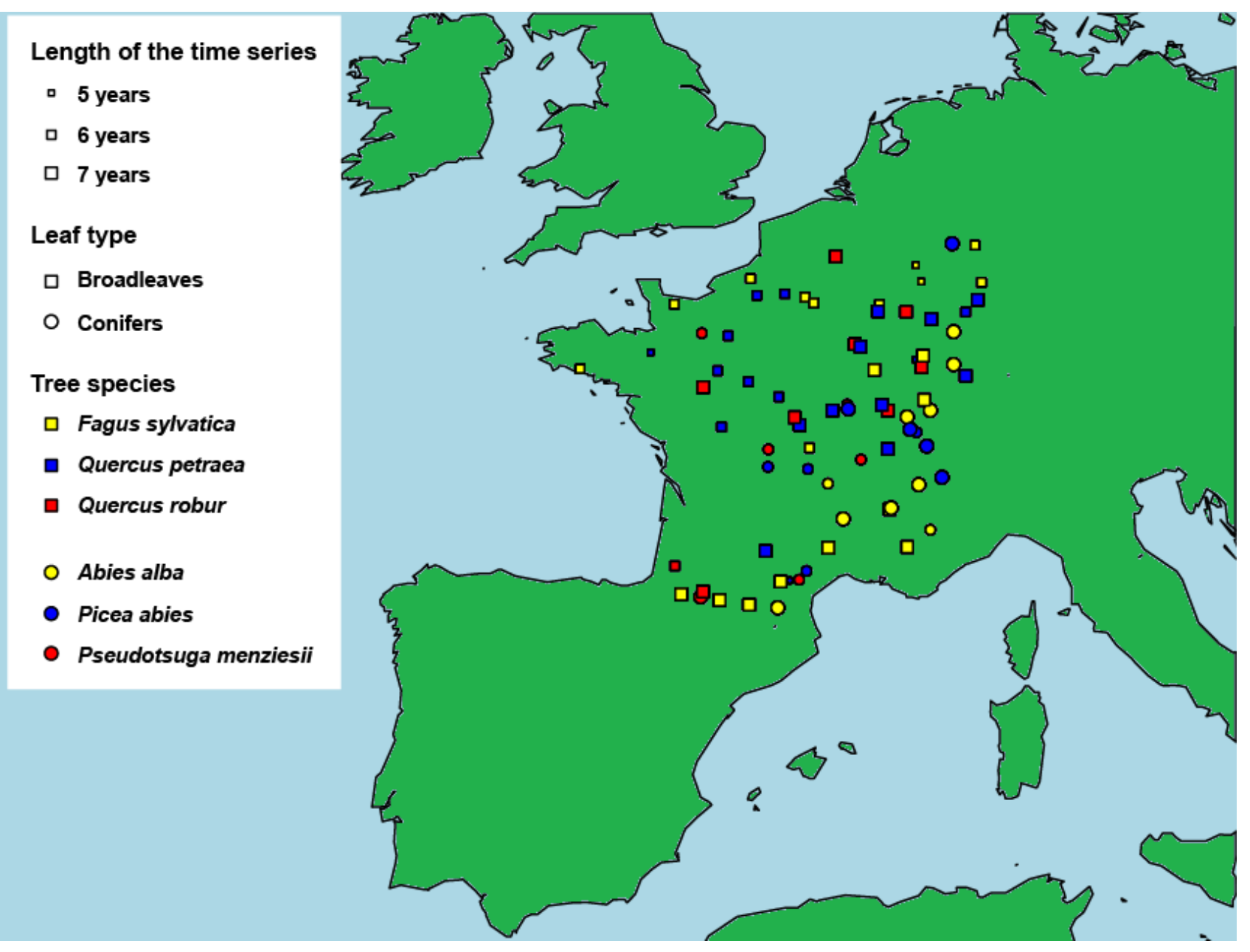


$563 \quad$ Figure 2

Seasonal NAO

\begin{tabular}{|c|c|c|c|c|}
\multicolumn{1}{c}{} & \multicolumn{1}{c}{ Winter } & \multicolumn{1}{c}{ Spring } & \multicolumn{1}{c}{ Summer } & \multicolumn{1}{c|}{ Autumn } \\
\cline { 2 - 5 } Precipitation & 0.12 & -0.25 & -0.19 & -0.40 \\
\cline { 2 - 5 } Temperature & 0.41 & 0.08 & -0.11 & -0.06 \\
\cline { 2 - 5 } NAO+ Weather & $\begin{array}{c}\text { warm } \\
\text { wet }\end{array}$ & $\begin{array}{c}\text { warm } \\
\text { dry }\end{array}$ & $\begin{array}{c}\text { cold } \\
\text { dry }\end{array}$ & $\begin{array}{c}\text { cold } \\
\text { dry }\end{array}$ \\
\cline { 2 - 5 } NAO- Weather - & $\begin{array}{c}\text { cold } \\
\text { dry }\end{array}$ & $\begin{array}{c}\text { cold } \\
\text { wet }\end{array}$ & $\begin{array}{c}\text { warm } \\
\text { wet }\end{array}$ & $\begin{array}{c}\text { warm } \\
\text { wet }\end{array}$ \\
\hline
\end{tabular}

$\beta$ weights

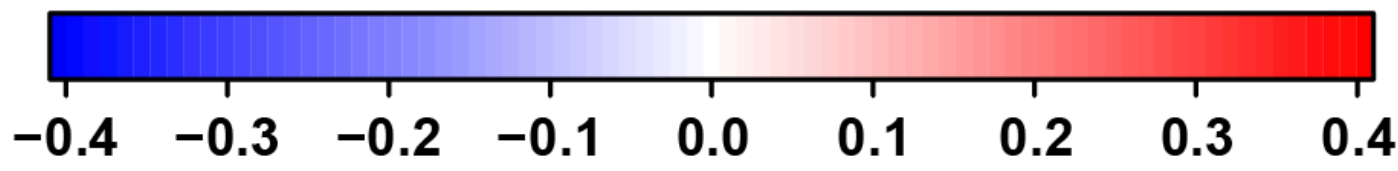


$566 \quad$ Figure 3 


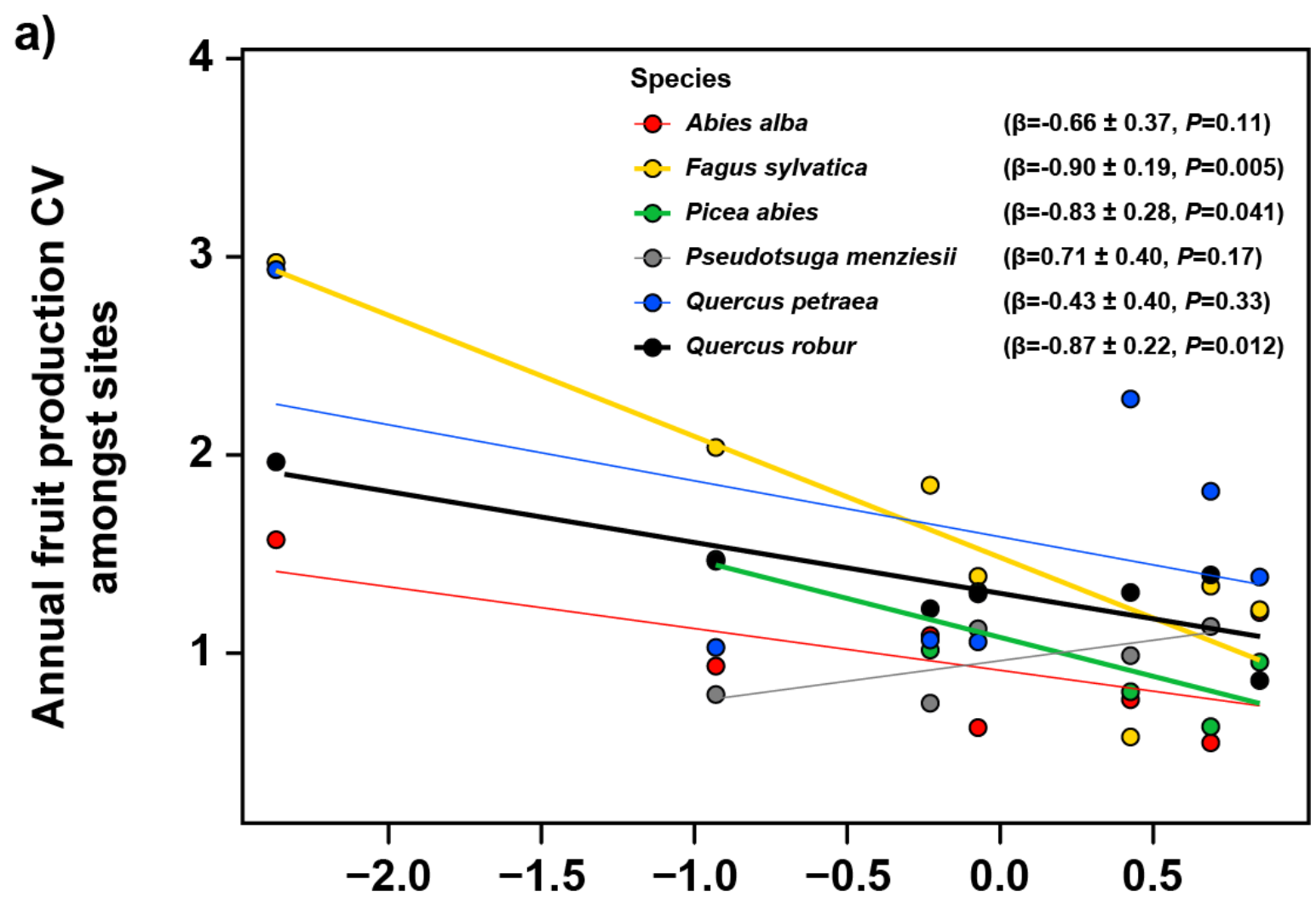

b)

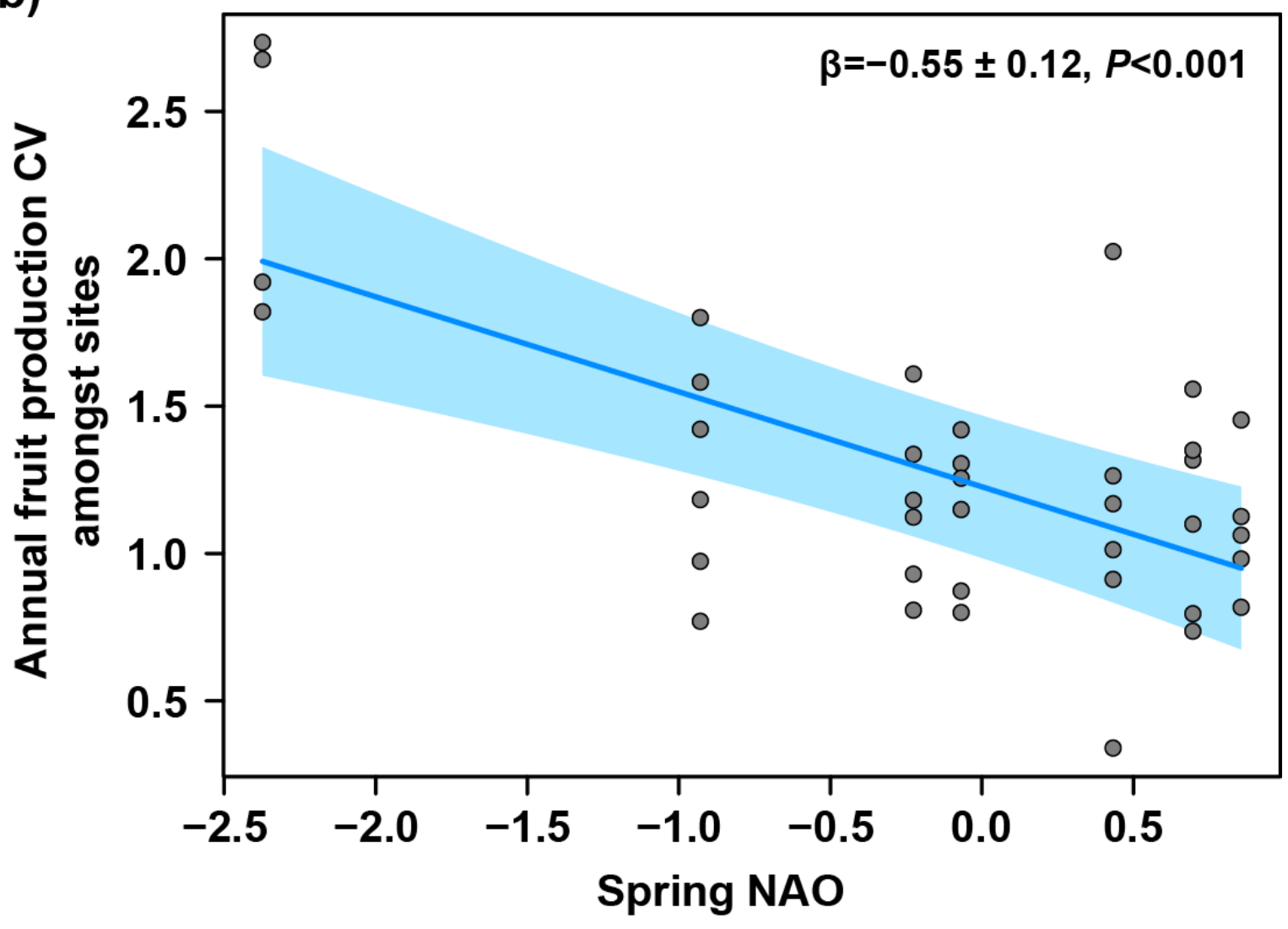


569 Table 1: Summary of the hypotheses discussed in this study for interannual variability and synchrony in fruit production. Our 570 analysis was focused on weather relationships with interannual variability and synchrony in fruit production, so only indirect 571 evidence of the weather relationships supporting or rejecting the hypotheses are presented.

\section{Indirect evidence}

\begin{tabular}{|c|c|c|c|}
\hline Hypothesis & Summary & Supports & Rejects \\
\hline \multicolumn{4}{|c|}{ a) Interannual variability } \\
\hline Resource matching & $\begin{array}{l}\text { Plants produce fruit as a direct } \\
\text { response to the available resources. }\end{array}$ & $\begin{array}{l}\text { Favourable weather for tree } \\
\text { productivity is positively correlated } \\
\text { with fruit production. }\end{array}$ & $\begin{array}{l}\text { No correlation with weather, or } \\
\text { weather cannot be associated with } \\
\text { higher tree productivity. }\end{array}$ \\
\hline Efficiency of pollination & $\begin{array}{l}\text { Synchronised and intermittent } \\
\text { flowering increases successful } \\
\text { pollination in wind-pollinated }\end{array}$ & $\begin{array}{l}\text { Favourable weather for pollination } \\
\text { (e.g. warm and dry springs) is } \\
\text { positively correlated with fruit } \\
\text { production. }\end{array}$ & $\begin{array}{l}\text { Favourable weather for pollination is } \\
\text { negatively or not correlated with fruit } \\
\text { production. }\end{array}$ \\
\hline
\end{tabular}

\section{b) Synchrony}

\section{The Moran effect}

Pollen coupling
Synchrony in fruit production is driven by synchrony meteorological conditions.

in trees can generate synchrony in fruit production amongst individuals by interacting with available resources.

$$
\text { hybrid }
$$
Favourable weather for pollination is
positively correlated with fruit production. Synchrony occurs within
Fruit production amongst sites is with the same correlated with different species at the local scale. 
572 Table 2: Summary of the specific aims of the study and the statistical tests performed.

\section{Questions}

Analyses

a) Meteorological variability

Do seasonal NAO indices correlate with seasonal weather at our sites?
Generalised linear mixed models (with site as random factor) correlating seasonal temperature and precipitation with seasonal NAO indices.

\section{b) Interannual variability in fruit production}

Do seasonal NAO indices correlate with fruit production?

Is fruit production best predicted by local meteorological variability or by seasonal NAO indices?

\section{c) Synchrony in fruit production}

For a given year, is variability in fruit production amongst sites associated with variability in meteorological conditions or to seasonal NAO indices?

Is fruit production (and weather) synchronised across sites within and amongst species?

Is synchrony of fruit production and weather between sites spatially dependent?

Does synchrony in fruit production between sites depend on synchrony in meteorological conditions and
Spearman correlations between fruit production and seasonal NAO indices per site.

Generalised linear mixed models per species (with site as random factor) correlating annual fruit production with seasonal temperatures, precipitation, and NAO indices.

Generalised linear mixed models per species (with site as random factor) correlating annual CV of fruit production amongst sites with annual CV of seasonal temperatures and precipitation and with seasonal NAO indices.

Temporal synchrony of fruit production, temperature, and precipitation amongst sites is calculated using Spearman correlations (i.e. correlation of time series $A$ vs. time series B).

Linear models correlating synchrony of fruit production and seasonal temperatures and precipitation between sites with geographical distance.

Linear models correlating synchrony of fruit production with synchrony of seasonal temperatures and precipitation and geographical distance between sites.

geographical distance? 
573 Table 3: Spearman's correlations between seasonal (autumn, winter, spring, and summer seasons prior to fruit production) 574 NAO indices and fruit production $(\rho \pm$ standard error) per species and leaf type. The $P$ values indicate whether average 575 correlation coefficients differ from 0 ( $t$-test). $N$ indicates the number of forests per species. Only forests with five or more years 576 of data were used in these analyses. The seasons are indicated by subscripts: $w, s p$, sm, and a indicate winter, spring, 577 summer, and autumn, respectively.

\begin{tabular}{|c|c|c|c|c|c|c|c|c|c|c|c|c|c|c|c|c|c|}
\hline & $\mathrm{NAO}_{\mathrm{a}}$ & & $\boldsymbol{P}$ & & $\mathrm{NAO}_{w}$ & & $\boldsymbol{P}$ & & $\mathrm{NAO}_{\text {sp }}$ & & $\boldsymbol{P}$ & & $\mathrm{NAO}_{\text {sm }}$ & & $\boldsymbol{P}$ & & $\mathbf{N}$ \\
\hline \multicolumn{18}{|l|}{ a) Species } \\
\hline Abies alba & $-0.34 \pm 0.10$ & $a b$ & 0.0031 & $* *$ & $-0.42 \pm 0.11$ & $\mathrm{~b}$ & 0.0007 & $* * *$ & $0.45 \pm 0.09$ & $a b$ & 0.0003 & $* * *$ & $-0.07 \pm 0.07$ & $\mathrm{~b}$ & 0.5433 & & 10 \\
\hline Picea abies & $-0.22 \pm 0.06$ & $a b$ & 0.0520 & . & $-0.42 \pm 0.07$ & $\mathrm{~b}$ & 0.0007 & $* * *$ & $0.13 \pm 0.15$ & $\mathrm{bc}$ & 0.2694 & & $0.27 \pm 0.12$ & $a b$ & 0.0141 & $*$ & 10 \\
\hline Pseudotsuga menziesii & $0.18 \pm 0.25$ & a & 0.2163 & & $-0.48 \pm 0.12$ & $b$ & 0.0026 & $* *$ & $-0.12 \pm 0.20$ & c & 0.4400 & & $0.00 \pm 0.22$ & $a b$ & 0.9772 & & 6 \\
\hline Fagus sylvatica & $0.06 \pm 0.07$ & a & 0.4089 & & $0.03 \pm 0.08$ & a & 0.7266 & & $0.61 \pm 0.06$ & a & 0.0000 & $* * *$ & $0.36 \pm 0.07$ & a & 0.0000 & $* * *$ & 21 \\
\hline Quercus petraea & $-0.39 \pm 0.08$ & $b$ & 0.0000 & $* * *$ & $0.09 \pm 0.10$ & a & 0.2810 & & $0.04 \pm 0.10$ & bc & 0.6014 & & $-0.06 \pm 0.06$ & $b$ & 0.4676 & & 20 \\
\hline Quercus robur & $-0.48 \pm 0.11$ & $\mathrm{~b}$ & 0.0001 & $* * *$ & $-0.14 \pm 0.11$ & $a b$ & 0.2786 & & $0.34 \pm 0.11$ & $a b c$ & 0.0092 & $* *$ & $-0.04 \pm 0.15$ & $\mathrm{~b}$ & 0.7297 & & 9 \\
\hline \multicolumn{18}{|l|}{ b) Leaf type } \\
\hline Conifers & $-0.18 \pm 0.08$ & a & 0.0341 & $*$ & $-0.43 \pm 0.06$ & $b$ & 0.0000 & $* * *$ & $0.20 \pm 0.09$ & a & 0.0253 & $*$ & $0.08 \pm 0.08$ & a & 0.2900 & & 26 \\
\hline Broadleaves & $-0.21 \pm 0.06$ & a & 0.0005 & $* * *$ & $0.02 \pm 0.06$ & a & 0.6490 & & $0.33 \pm 0.06$ & a & 0.0000 & $* * *$ & $0.12 \pm 0.05$ & a & 0.0250 & $*$ & 50 \\
\hline
\end{tabular}


578 Table 4: Summary of the models predicting fruit production per species. Standardised 579 coefficients are shown as model estimates $(\beta \pm$ standard error (SE)). $\triangle \mathrm{BIC}$ indicates the 580 variable importance of the predictors and is calculated as the difference of BIC between the 581 entire model and the model without the predictor of interest. Variance explained by the fixed 582 factors $\left(R^{2} \mathrm{~m}\right)$ and by the entire model $\left(R^{2} \mathrm{c}\right)$ is also shown. All coefficients were significant at the 5830.05 level. The seasons are indicated by subscripts: $w, s p, s m$, and a indicate winter, spring, 584 summer, and autumn, respectively.

\begin{tabular}{lcccc} 
& $\boldsymbol{\beta} \pm \mathrm{SE}$ & $\Delta \mathrm{BIC}$ & $\boldsymbol{R}_{\mathrm{m}}{ }^{2}$ & $\boldsymbol{R}^{2}$ \\
\hline Abies alba & & & & \\
$\mathbf{N A O}_{\mathrm{w}}$ & $-0.40 \pm 0.10$ & 10.81 & & \\
$\mathbf{N A O}_{\text {sp }}$ & $0.42 \pm 0.09$ & 13.59 & & \\
$\mathbf{P}_{\mathrm{w}}$ & $-0.29 \pm 0.11$ & 0.90 & & \\
Model & & & 0.39 & 0.47
\end{tabular}

\section{Picea abies}

$\begin{array}{lcc}\mathrm{NAO}_{\text {sm }} & 0.31 \pm 0.07 & 11.51 \\ \mathbf{P}_{\text {sp }} & -0.32 \pm 0.12 & 2.62 \\ \mathbf{P}_{\mathrm{w}} & 0.49 \pm 0.12 & 11.41 \\ \mathrm{~T}_{\mathrm{sm}} & 0.38 \pm 0.18 & 0.52\end{array}$

$\begin{array}{lll}\text { Model } & 0.26 & 0.79\end{array}$

\begin{tabular}{lrrrr}
\multicolumn{2}{l}{ Pseudotsuga menziesii } & & & \\
NAO $_{\mathrm{a}}$ & $0.39 \pm 0.10$ & 10.63 & & \\
$\mathrm{NAO}_{\mathrm{w}}$ & $-0.29 \pm 0.11$ & 3.78 & & \\
$\mathrm{~T}_{\text {sp }}$ & $0.57 \pm 0.14$ & 4.33 & & \\
Model & & & 0.52 & 0.52
\end{tabular}

Fagus sylvatica

$\begin{array}{lllll}\text { NAO }_{a} & 0.48 \pm 0.07 & 34.37 & & \\ \text { NAO }_{\text {sp }} & 0.85 \pm 0.07 & 88.22 & & \\ \mathbf{P}_{\text {sm }} & -0.22 \pm 0.08 & 3.95 & & \\ \mathbf{T}_{\mathbf{a}} & -0.16 \pm 0.07 & 0.14 & & \\ \text { Model } & & & 0.51 & 0.55\end{array}$

Quercus petraea

$\begin{array}{llcll}\text { NAO }_{a} & -0.20 \pm 0.08 & 0.90 & & \\ \mathbf{T}_{\mathrm{a}} & 0.35 \pm 0.08 & 11.89 & & \\ \text { Model } & & & 0.21 & 0.21\end{array}$

$\begin{array}{lcccc}\text { Quercus robur } & & & & \\ \mathbf{P}_{\mathrm{sm}} & 0.30 \pm 0.12 & 1.42 & & \\ \mathbf{T}_{\mathrm{a}} & 0.72 \pm 0.16 & 14.34 & & \\ \mathbf{T}_{\mathrm{w}} & -0.38 \pm 0.15 & 2.45 & & \\ \text { Model } & & & 0.26 & 0.28\end{array}$


588 Table 5: a) Average synchrony (average Spearman's correlation of fruit production between 589 sites: $\rho \pm$ standard error) in annual fruit production (NPP), seasonal temperature (T), and 590 precipitation $(\mathrm{P})$ between sites within species. b) Standardised slopes between synchrony and 591 geographical distance $(\beta \pm$ standard error). Bold coefficients indicate values that differ from 592 zero at the 0.05 level (t-test). $N$ indicates the number of pairwise comparisons. The seasons 593 are indicated by subscripts: w, sp, sm, and a indicate winter, spring, summer, and autumn, 594 respectively.
A. alba
P. abies
P. menziesii F. sylvatica
Q. petraea
Q. robur

a) Synchrony ( $\rho)$

$\begin{array}{lllllll}\text { Fruit NPP } & 0.36 \pm 0.07 & 0.31 \pm 0.08 & 0.19 \pm 0.20 & 0.60 \pm 0.02 & 0.20 \pm 0.04 & 0.29 \pm 0.07 \\ \mathrm{~T}_{\mathrm{w}} & 0.90 \pm 0.01 & 0.89 \pm 0.02 & 0.82 \pm 0.02 & 0.89 \pm 0.01 & 0.96 \pm 0.01 & 0.94 \pm 0.01 \\ \mathrm{~T}_{\text {sp }} & 0.73 \pm 0.03 & 0.70 \pm 0.05 & 0.72 \pm 0.07 & 0.74 \pm 0.02 & 0.85 \pm 0.01 & 0.78 \pm 0.03 \\ \mathrm{~T}_{\text {sm }} & 0.96 \pm 0.01 & 0.95 \pm 0.01 & 0.94 \pm 0.02 & 0.94 \pm 0.01 & 0.96 \pm 0.01 & 0.95 \pm 0.01 \\ \mathrm{~T}_{\mathrm{a}} & 0.81 \pm 0.02 & 0.82 \pm 0.03 & 0.73 \pm 0.06 & 0.69 \pm 0.02 & 0.79 \pm 0.01 & 0.85 \pm 0.02 \\ \mathrm{P}_{\mathrm{w}} & 0.71 \pm 0.04 & 0.80 \pm 0.03 & 0.34 \pm 0.15 & 0.44 \pm 0.03 & 0.68 \pm 0.02 & 0.38 \pm 0.08 \\ \mathrm{P}_{\text {sp }} & 0.62 \pm 0.04 & 0.56 \pm 0.07 & 0.62 \pm 0.08 & 0.53 \pm 0.03 & 0.58 \pm 0.03 & 0.67 \pm 0.03 \\ \mathrm{P}_{\text {sm }} & 0.56 \pm 0.04 & 0.61 \pm 0.07 & 0.39 \pm 0.14 & 0.42 \pm 0.03 & 0.77 \pm 0.01 & 0.65 \pm 0.05 \\ \mathrm{P}_{\mathrm{a}} & 0.61 \pm 0.05 & 0.74 \pm 0.03 & 0.57 \pm 0.13 & 0.49 \pm 0.03 & 0.68 \pm 0.02 & 0.59 \pm 0.04\end{array}$

\section{b) 6 with distance}

\begin{tabular}{|c|c|c|c|c|c|c|}
\hline Fruit NPP & $-0.20 \pm 0.16$ & $-0.35 \pm 0.21$ & $-0.39 \pm 0.38$ & $-0.06 \pm 0.08$ & $-0.01 \pm 0.09$ & $-0.71 \pm 0.13$ \\
\hline$T_{w}$ & $-0.65 \pm 0.13$ & $-0.69 \pm 0.16$ & $-0.29 \pm 0.39$ & $-0.54 \pm 0.07$ & $-0.33 \pm 0.08$ & $-0.79 \pm 0.12$ \\
\hline $\mathbf{T}_{\mathrm{sp}}$ & $-0.62 \pm 0.13$ & $-0.44 \pm 0.20$ & $-0.75 \pm 0.27$ & $-0.67 \pm 0.06$ & $-0.70 \pm 0.06$ & $-0.82 \pm 0.11$ \\
\hline$T_{s m}$ & $-0.52 \pm 0.14$ & $-0.22 \pm 0.22$ & $-0.06 \pm 0.41$ & $-0.41 \pm 0.07$ & $-0.07 \pm 0.09$ & $-0.65 \pm 0.14$ \\
\hline$T_{\text {fall }}$ & $-0.51 \pm 0.14$ & $-0.56 \pm 0.19$ & $-0.02 \pm 0.41$ & $-0.44 \pm 0.07$ & $-0.32 \pm 0.08$ & $-0.50 \pm 0.16$ \\
\hline $\mathbf{P}_{\mathrm{w}}$ & $-0.86 \pm 0.08$ & $-0.45 \pm 0.20$ & $-0.75 \pm 0.27$ & $-0.58 \pm 0.06$ & $-0.21 \pm 0.08$ & $-0.68 \pm 0.14$ \\
\hline $\mathbf{P}_{\mathrm{sp}}$ & $-0.75 \pm 0.11$ & $-0.31 \pm 0.21$ & $-0.03 \pm 0.41$ & $-0.35 \pm 0.07$ & $-0.37 \pm 0.08$ & $-0.04 \pm 0.19$ \\
\hline $\mathbf{P}_{\mathrm{sm}}$ & $-0.41 \pm 0.15$ & $-0.67 \pm 0.17$ & $-0.54 \pm 0.34$ & $-0.36 \pm 0.07$ & $-0.47 \pm 0.08$ & $-0.61 \pm 0.15$ \\
\hline$P_{\text {fall }}$ & $-0.79 \pm 0.10$ & $-0.64 \pm 0.17$ & $-0.30 \pm 0.39$ & $-0.58 \pm 0.06$ & $-0.60 \pm 0.07$ & $-0.79 \pm 0.12$ \\
\hline$N$ & 38 & 22 & 8 & 163 & 135 & 30 \\
\hline
\end{tabular}


596 Table 6: Average synchrony (Spearman's $\rho \pm$ standard error) between sites within and amongst species. Comparisons 597 amongst leaf types and all sites are also shown. Bold coefficients indicate values that differ from zero at the 0.05 level ( $t$-test).

598 The number of comparisons is shown in brackets below each coefficient. Only comparisons with five or more years of shared 599 data were used.

\begin{tabular}{|c|c|c|c|c|c|c|}
\hline & Abies alba & Picea abies & Pseudotsuga menziesii & Fagus sylvatica & Quercus petraea & Quercus robu \\
\hline Abies alba & $\begin{array}{c}0.36 \pm 0.07 \\
(38)\end{array}$ & $\begin{array}{c}0.07 \pm 0.07 \\
(53)\end{array}$ & $\begin{array}{c}0.10 \pm 0.06 \\
\quad(23)\end{array}$ & $\begin{array}{c}\mathbf{0 . 2 0} \pm \mathbf{0 . 0 3} \\
(161)\end{array}$ & $\begin{array}{c}0.12 \pm 0.03 \\
\quad(116)\end{array}$ & $\begin{array}{c}0.26 \pm 0.03 \\
(81)\end{array}$ \\
\hline Picea abies & $\begin{array}{c}0.07 \pm 0.07 \\
\quad(53)\end{array}$ & $\begin{array}{c}0.31 \pm 0.08 \\
(22)\end{array}$ & $\begin{array}{l}0.02 \pm 0.06 \\
\quad(24)\end{array}$ & $\begin{array}{l}0.08 \pm 0.04 \\
\quad(130)\end{array}$ & $\begin{array}{c}0.09 \pm 0.04 \\
(113)\end{array}$ & $\begin{array}{l}0.04 \pm 0.04 \\
\quad(46)\end{array}$ \\
\hline Pseudotsuga menziesii & $\begin{array}{l}0.10 \pm 0.06 \\
\quad(23)\end{array}$ & $\begin{array}{c}0.02 \pm 0.06 \\
(24)\end{array}$ & $\begin{array}{c}0.19 \pm 0.20 \\
(8)\end{array}$ & $\begin{array}{c}-0.10 \pm 0.05 \\
(65)\end{array}$ & $\begin{array}{c}-0.07 \pm 0.05 \\
(86)\end{array}$ & $\begin{array}{c}-0.13 \pm 0.10 \\
(19)\end{array}$ \\
\hline Fagus sylvatica & $\begin{array}{c}0.20 \pm 0.03 \\
(161)\end{array}$ & $\begin{array}{c}0.08 \pm 0.04 \\
(130)\end{array}$ & $\begin{array}{c}-0.10 \pm 0.05 \\
(65)\end{array}$ & $\begin{array}{c}0.60 \pm 0.02 \\
(163)\end{array}$ & $\begin{array}{c}-0.12 \pm 0.03 \\
(279\end{array}$ & $\begin{array}{c}0.10 \pm 0.04 \\
\quad(141)\end{array}$ \\
\hline Quercus petraea & $\begin{array}{l}0.12 \pm 0.03 \\
\quad(116)\end{array}$ & $\begin{array}{c}0.09 \pm 0.04 \\
(113)\end{array}$ & $\begin{array}{c}-0.07 \pm 0.05 \\
(86)\end{array}$ & $\begin{array}{c}-0.12 \pm 0.03 \\
(279)\end{array}$ & $\begin{array}{c}0.20 \pm 0.04 \\
\quad(135)\end{array}$ & $\begin{array}{c}0.28 \pm 0.04 \\
(97)\end{array}$ \\
\hline Quercus robur & $\begin{array}{c}0.26 \pm 0.03 \\
(81)\end{array}$ & $\begin{array}{c}0.04 \pm 0.04 \\
(46)\end{array}$ & $\begin{array}{c}-0.13 \pm 0.10 \\
(19)\end{array}$ & $\begin{array}{c}0.10 \pm 0.04 \\
\quad(141)\end{array}$ & $\begin{array}{c}0.28 \pm 0.04 \\
(97)\end{array}$ & $\begin{array}{c}0.29 \pm 0.07 \\
(30)\end{array}$ \\
\hline
\end{tabular}

\section{Comparisons amongst leaf types}

$\begin{array}{lc}\text { Broadleaves } & \begin{array}{c}0.17 \pm 0.02 \\ (845)\end{array} \\ \text { Conifers } & \begin{array}{c}0.17 \pm 0.03 \\ (168)\end{array} \\ & 0.12 \pm 0.01 \\ \text { All species } & (1830)\end{array}$


602 Table 7: Summary of the models correlating synchrony $(\rho)$ of fruit production between sites 603 with synchrony in meteorological conditions. Coefficients are $\beta$ weights \pm standard error. $R^{2}$ 604 indicates the total variance explained by the model. All coefficients were statistically significant 605 at the 0.05 level. Only comparisons with five or more years of shared data were used in the 606 models. The variables of seasonal temperature and precipitation are indicated by $T$ and $P$, 607 respectively. The seasons are indicated by subscripts: $w, s p, s m$, and a indicate winter, spring, 608 summer, and autumn, respectively.

\section{$\begin{array}{lllll}\text { A. alba } & \text { P. abies } & \text { F. sylvatica } & \text { Q.petraea } & \text { Q. robur }\end{array}$}

Distance

$-0.71 \pm 0.13$

$T_{a}$

$0.45 \pm 0.15$

$\mathbf{P}_{\mathrm{w}}$

$0.20 \pm 0.08$

$\mathbf{P}_{\mathrm{sm}}$

$0.20 \pm 0.09$

$R^{2}$

0.20

0.04

0.04

0.50

Comparisons

38

22

163

135

30 